\title{
Supporting Information Influence of Particle Size and Shapes on the Antifungal Activities of Greener Nanostructured Copper against Penicillium italicum
}

Francis J. Osonga, ${ }^{1}$ Gaddi Eshun, ${ }^{1}$ Sanjay Kalra, ${ }^{2}$ Idris Yazgan, ${ }^{2+}$ Laura Sakhaee, ${ }^{2}$ Renata Ontman, ${ }^{2}$ Shaojie Jiang, ${ }^{2} \&$ Omowunmi A. Sadik ${ }^{1 *}$

${ }^{1}$ BioSensor Materials for Advanced Research and Technology (The BioSMART Center), Chemistry and Environmental Science Department, New Jersey Institute of Technology, University Heights, 161 Warren Street, Newark, NJ 07102

${ }^{2}$ Department of Chemistry, Center for Research in Advanced Sensing Technologies \& Environmental Sustainability (CREATES), State University of New York at Binghamton, PO Box 6000 Binghamton, NY, 13902-6000. 

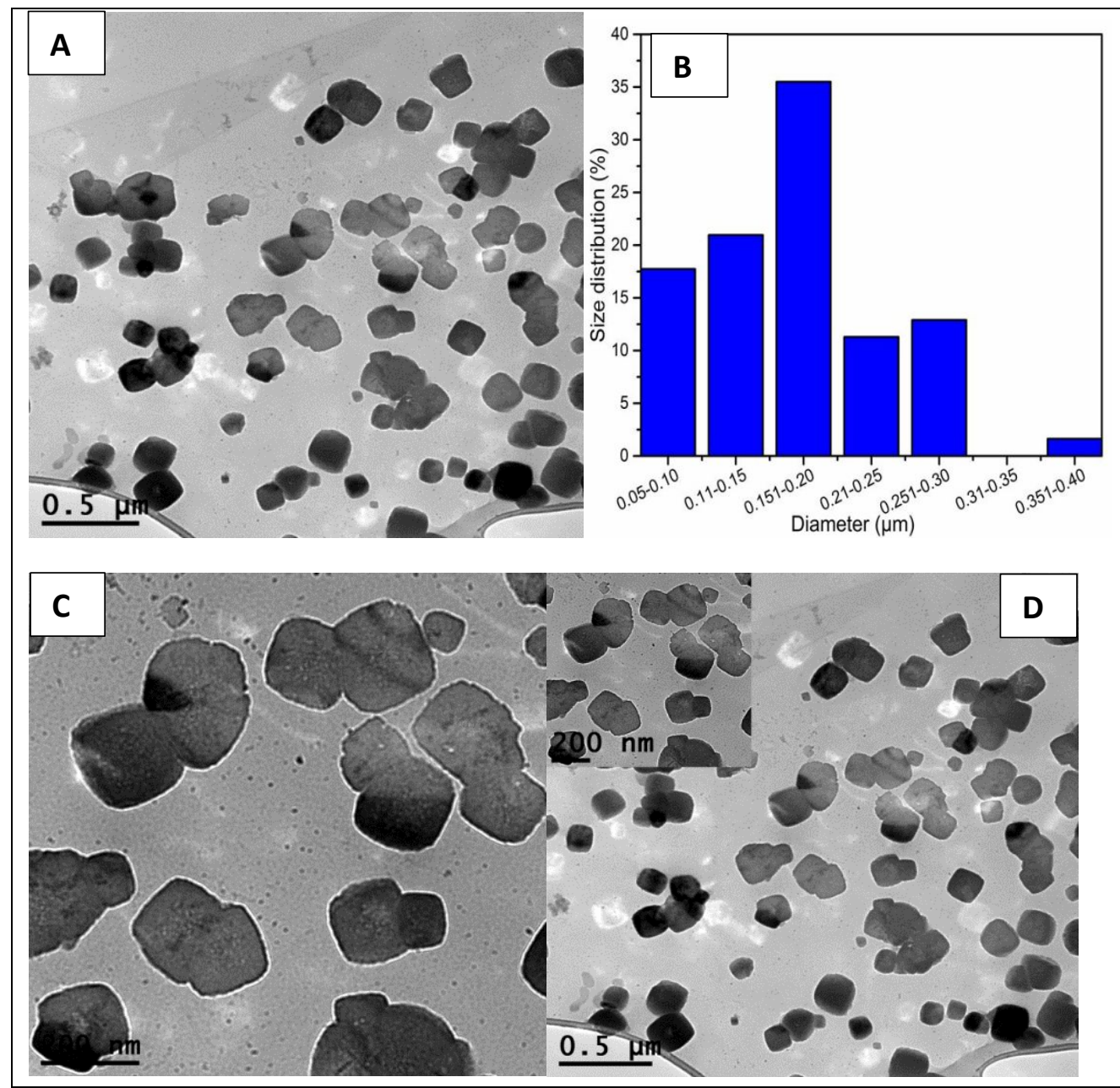

Fig. S1: TEM images showing a mixture of nanocubes and irregular nanocubes for sample S5. 


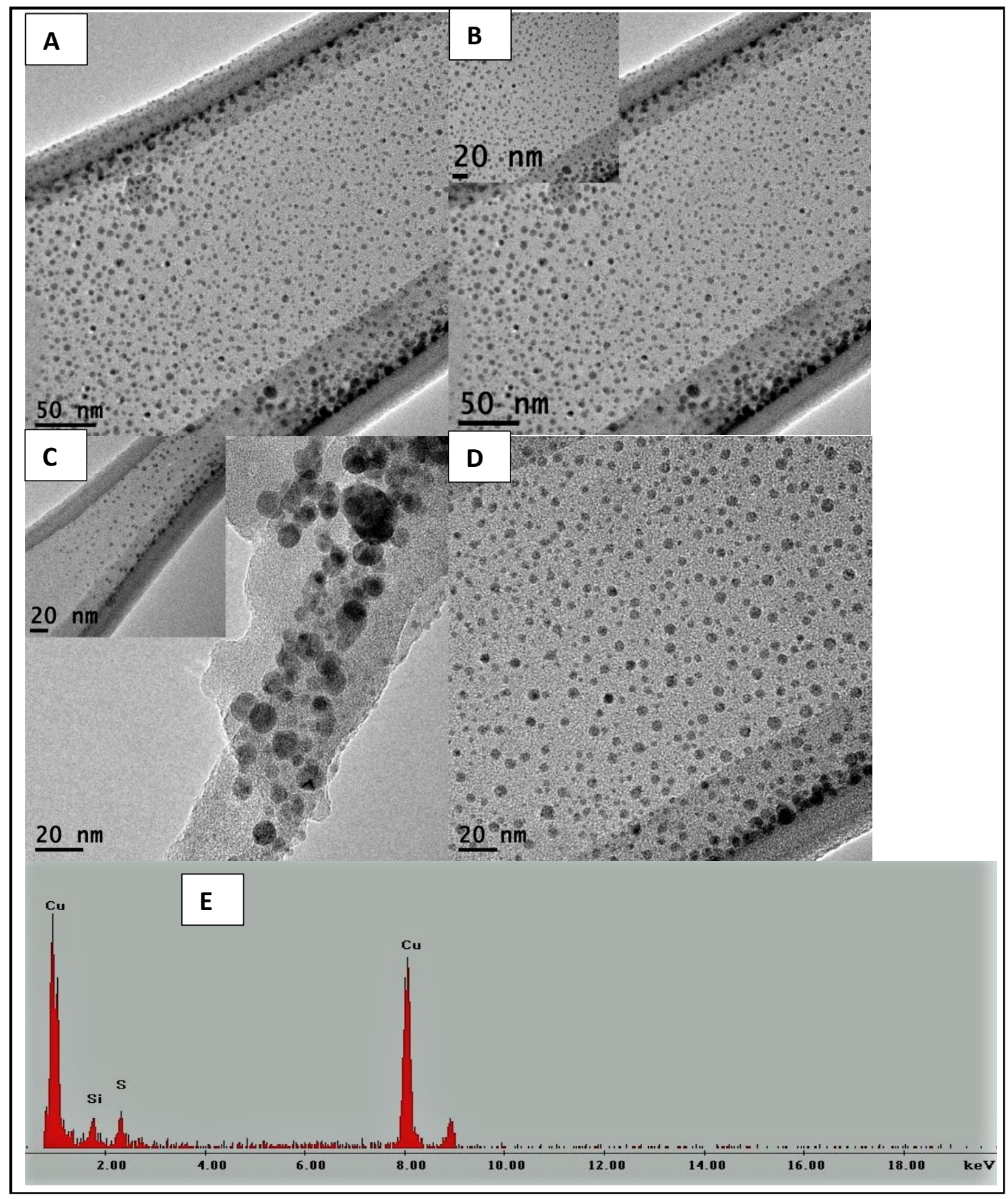

Fig.S2: Copper nanospheres (A, B, C, D) with diameter sizes ranging from $1 \mathrm{~nm}-5 \mathrm{~nm}$ are formed at a low ratio of below 1:1 of QDP: $\mathrm{CuSO}_{4}$ concentrations and the EDX spectrum of copper nanospheres $(\mathrm{E})$. 


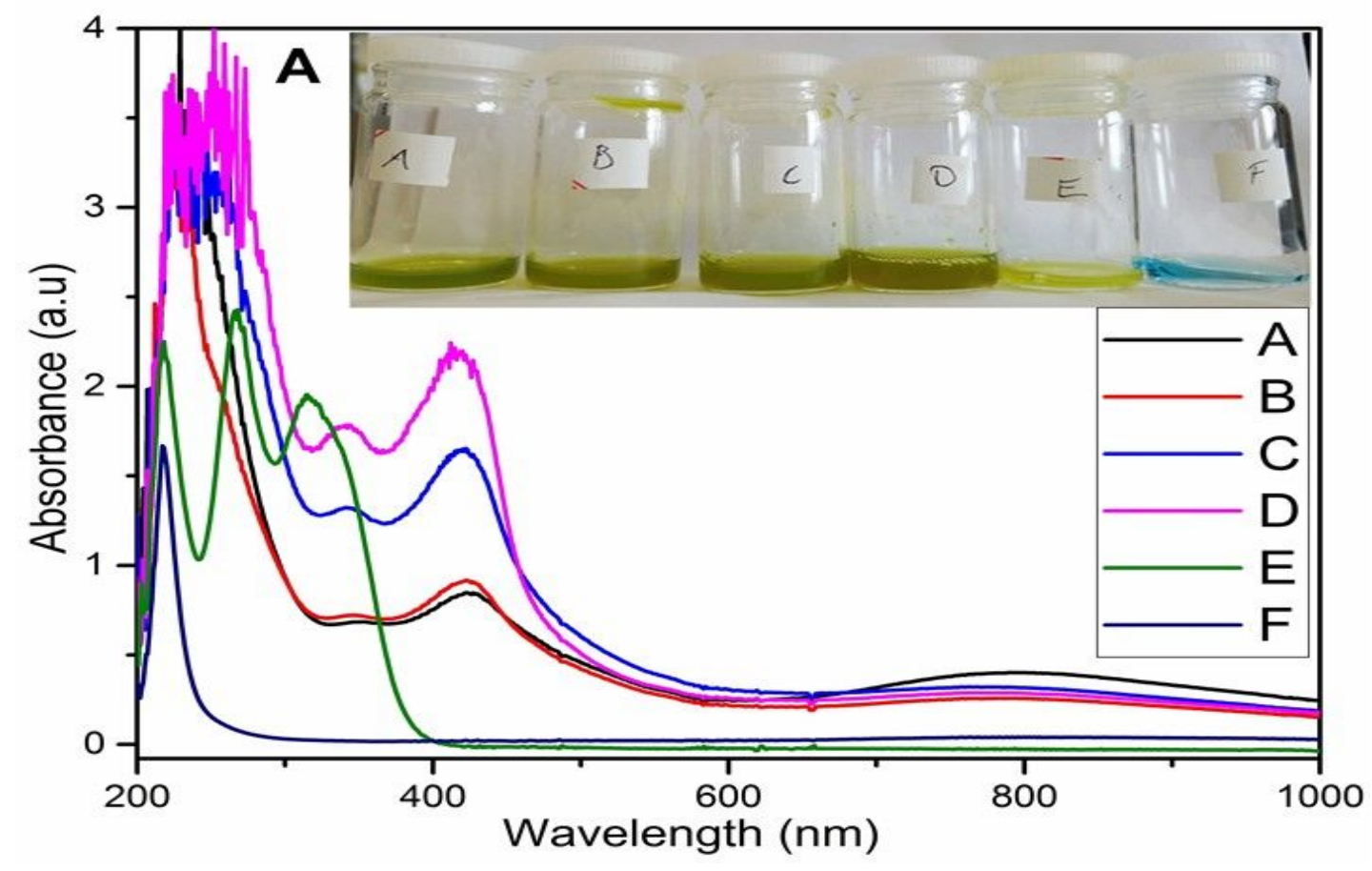

Fig.S3: UV-Vis spectroscopy showing the formation of copper nanospheres for the reaction in which varied concentration of $5 \mathrm{mM}$ QDP was reacted with a constant concentration of $5 \mathrm{mM}$ $\mathrm{CuSO}_{4}$ (A) Inset is the pictorial image showing color change of light green depicting the formation of copper nanoparticles. 


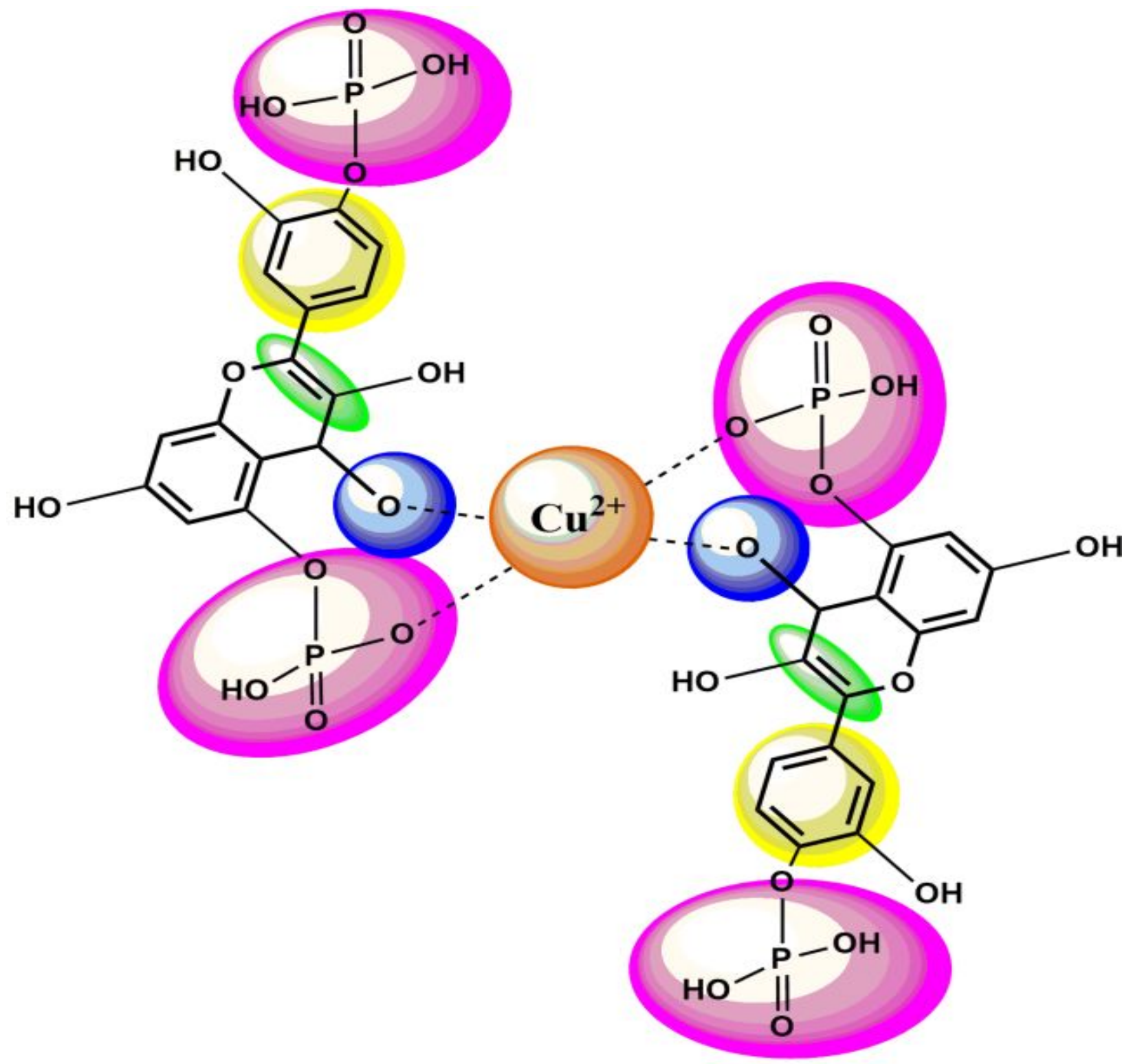

Fig.S4: Possible interaction of $\mathrm{Cu}^{2+}$ with QDP molecule leading to reduction to elemental copper. 


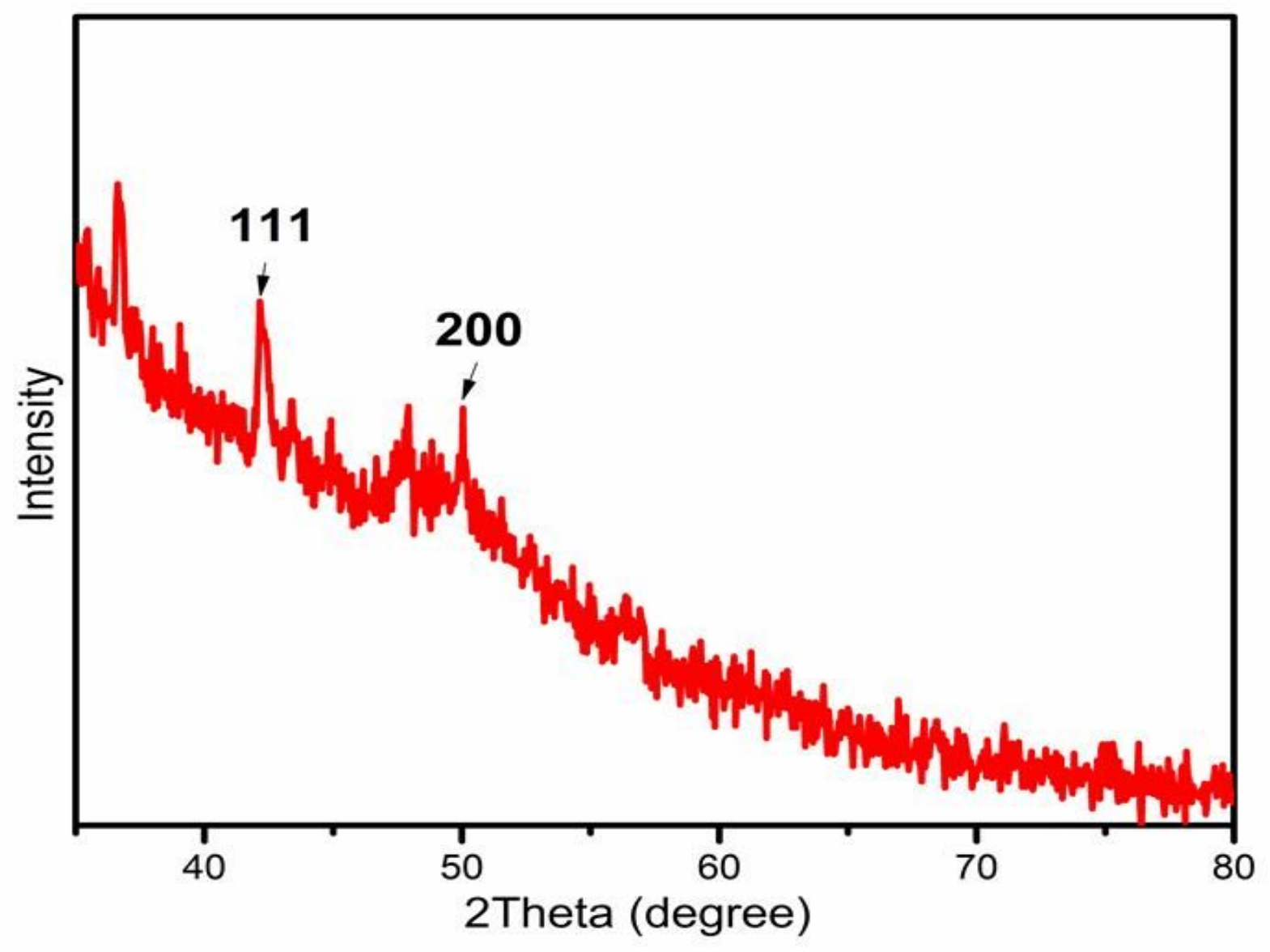

Fig. S5: Powdered XRD pattern of copper nanospheres 
Table S1: Data table showing metric analysis of the synthesis of copper nanocubes by reacting Quercetin diphosphate and copper (ii) sulfate

\begin{tabular}{|c|c|c|c|c|}
\hline \multirow[b]{2}{*}{ Item } & \multicolumn{4}{|c|}{ Greener method of synthesis of copper nanocubes } \\
\hline & Amount used & Moles & Mass (g) & Metric value \\
\hline \multicolumn{5}{|l|}{ Reagents } \\
\hline $\begin{array}{l}\text { Quercetin } \\
\text { diphosphate }\end{array}$ & $400 \mu \mathrm{L}, 5 \mathrm{mmol} / \mathrm{L}$ & 0.000002 & 0.000924 & \\
\hline $\begin{array}{l}\text { Copper (II) Sulphate } \\
\left(\mathrm{CuSO}_{4} .5 \mathrm{H}_{2} \mathrm{O}\right)\end{array}$ & $200 \mu \mathrm{L}, 0.5 \mathrm{moles} / \mathrm{L}$ & 0.0001 & 0.024968 & \\
\hline \multicolumn{5}{|l|}{ Solvents } \\
\hline Water & $5 \mathrm{~mL}$ & 0.277469 & 5.000 & \\
\hline \multicolumn{5}{|l|}{ Metrics } \\
\hline Yield & $0.005846 \mathrm{~g}$ & 0.000091996 & $0.005846 \mathrm{~g}, 92 \%$ & \\
\hline $\mathrm{AE}(\%)$ & & & & 73.56 \\
\hline PMI & & & & 5.429 \\
\hline $\mathrm{ME}(\%)$ & & & & 0.9019 \\
\hline E-factor & & & & 3.429 \\
\hline
\end{tabular}




\section{S5: Calculations of metric values}
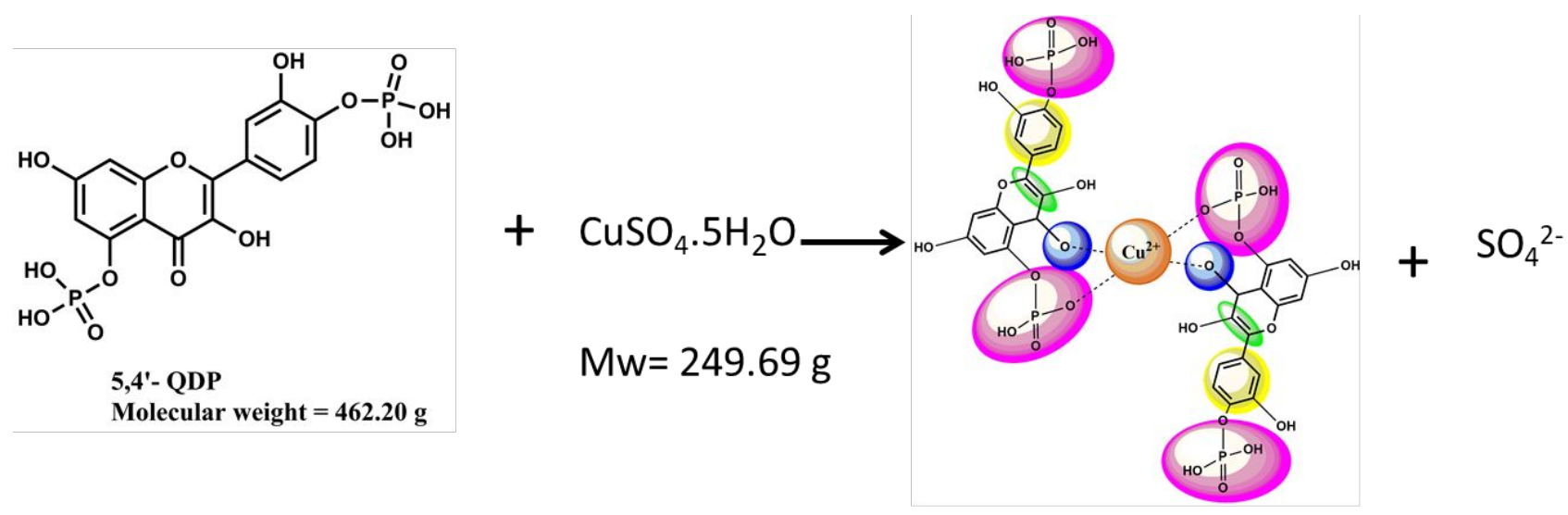

$M w=460+63.55=523.65 \mathrm{~g}$

Molecular weight of reactants $=462.20 \mathrm{~g}+249.69 \mathrm{~g}=711.89 \mathrm{~g}$

Molecular weight of desired product $=523.65 \mathrm{~g}$

Molecular weight of desired product copper only $=63.55 \mathrm{~g}$

Atom Economy $(\mathrm{AE})=\left(\frac{\text { Molecular weight of desired product structure }}{\sum \text { Molecular weight of reactants }}\right) \times 100$

$=(523.65 \mathrm{~g} / 711.89 \mathrm{~g}) \times 100=73.558 \%$

Molar Efficiency $(\mathrm{ME})=\left(\frac{\text { Moles of the product }}{\sum \text { Moles of reactants }}\right) \times 100$

$$
=(0.000002+0.0001) \text { moles } / 0.000091996 \text { moles }=0.9019 \%
$$

Process Mass Intensity $(\mathrm{PMI})=\left(\frac{\sum \text { Mass of reactants and recovered product }}{\text { Mass of recovered product }}\right)$

$$
=(0.000924+0.024968+0.005846) \mathrm{g} / 0.005846 \mathrm{~g}=5.429
$$

Environmental factor $($ E-factor $)=\frac{\text { Mass of total waste }}{\text { Mass of product }}$

Total mass of reactant $=0.000924 \mathrm{~g}+0.024968 \mathrm{~g}=0.025892 \mathrm{~g}$ 
Amount of final product $=0.005846 \mathrm{~g}$

Amount of waste $=(0.025892-0.005846) \mathrm{g}=0.020046 \mathrm{~g}$

E-factor $=0.020046 \mathrm{~g} / 0.005846 \mathrm{~g}=3.429$ 